\title{
Malignant transformation in 5071 southern Taiwanese patients with potentially malignant oral mucosal disorders
}

\author{
Yen-Yun Wang ${ }^{1,2}$, Yen-Hsuan Tail ${ }^{3}$, Wen-Chen Wang ${ }^{4,5}$, Ching-Yi Chen ${ }^{4}$, Yu-Hsun Kao ${ }^{1}$, Yuk-Kwan Chen ${ }^{4,5,6^{*}}$ \\ and Chung-Ho Chen ${ }^{3,5^{*}}$
}

\begin{abstract}
Background: Oral cancers can be preceded by clinically evident oral potentially malignant disorders (OPMDs). The current study evaluated the rate and the time of malignant transformation in the various OPMDs in a cohort of patients from southern Taiwan. Parameters possibly indicative for malignant transformation of OPMDs, such as epidemiological and etiological factors, and clinical and histopathological features were also described.

Methods: We followed-up 5071 patients with OPMDs-epithelial dysplasia with oral submucous fibrosis, epithelial dysplasia with hyperkeratosis/epithelial hyperplasia, hyperkeratosis/epithelial hyperplasia, oral submucous fibrosis, lichen planus, and verrucous hyperplasia-between 2001 and 2010 for malignant transformation.

Results: Two hundred nineteen of these 5071 OPMD patients (202 men, 17 women; mean age: 51.25 years; range: 30-81 years) developed oral cancers (179 squamous cell carcinomas; 40 verrucous carcinomas) in the same sites as the initial lesions at least 6 months after their initial biopsies. The overall transformation rate was $4.32 \%$ (mean duration of transformation: 33.56 months; range: 6-67 months). Additionally, the mean time of malignant transformation was significantly shorter for lesions with than without epithelial dysplasia. The risk of malignant transformation was 1.89 times higher for epithelially dysplastic than non-dysplastic lesions. The anatomical site of OPMD and the presence of epithelial dysplasia were significantly associated with malignant transformation. The hazard rate ratio was 1.87 times larger for tongue lesions than for buccal lesions.
\end{abstract}

Conclusion: Patients with OPMDs require long-term follow up.

Keywords: Oral potentially malignant disorders, Malignant transformation, Oral epithelial dysplasia, Oral squamous cell carcinoma

\section{Background}

Oral squamous-cell carcinoma (OSCC) accounts for more than $90 \%$ of oral malignancies and is the 11th most common cancer worldwide; it provides $3 \%$ of all newly diagnosed cancer cases [1,2]. Because of the high prevalence $(16.5 \%$ in men) of betel quid chewers in Taiwan [3], OSCC is one of the leading types of cancer; it is the fourth most frequently occurring cancer and the fifth leading cause of cancer death in men in Taiwan [4].

\footnotetext{
*Correspondence: k840042@gmail.com; chench@cc.kmu.edu.tw

${ }^{4}$ Division of Oral Pathology and Maxillofacial Radiology, Kaohsiung Medical

University Hospital, Kaohsiung, Taiwan

${ }^{3}$ Division of Oral and Maxillofacial Surgery, Department of Dentistry,

Kaohsiung Medical University Hospital, Kaohsiung, Taiwan

Full list of author information is available at the end of the article
}

The claims in recent research that the five-year survival rate of oral cancers is still low might be attributable to most cases of OSCCs being diagnosed at an advanced stage. The five-year survival rate of early stage (I and II) OSCC might be about $80 \%$, but of advanced stage (III and IV) OSCC is only approximately 20\% [5]. Because most cases of OSCC are preceded by clinically evident oral potentially malignant disorders (OPMDs), it is important to prevent malignant change for those patients diagnosed with OPMDs [6].

In our review of the English literature, we found only a few studies that focused on the malignant transformation potentials of various OPMDs. Hsue et al. [7] found that the malignant transformation rates of a cohort of 1458 
patients with OPMDs were $5.4 \%$ for epithelial dysplasia with oral submucous fibrosis, $4.65 \%$ for epithelial dysplasia with hyperkeratosis/epithelial hyperplasia, $3.55 \%$ for hyperkeratosis/epithelial hyperplasia, 3.09\% for verrucous hyperplasia, $2.1 \%$ for lichen planus, and $1.9 \%$ for oral submucous fibrosis; the overall malignant transformation rate was $3.02 \%$ and the average time for transformation was 42.64 months. In contrast, another study [8] reported that the malignant transformation rates of OPMDs in southern Taiwan were $24.24 \%$ for oral epithelial dysplasia, $20.00 \%$ for verrucous hyperplasia, $8.57 \%$ for hyperkeratosis/epithelial hyperplasia, and $0.00 \%$ for oral submucous fibrosis.

We investigated and updated the rate and the time of malignant transformation in a wide spectrum of potentially malignant oral epithelial lesions in a cohort of patients from Southern Taiwan. Moreover, parameters possibly indicative for malignant transformation of OPMDs, such as epidemiological and etiological factors, and clinical and histopathological features were described.

\section{Methods}

The Oral Pathology Department and Oral \& Maxillofacial (OMF) Surgery Department of the hospital not only provides services for nearly all the biopsied OMF lesions but is also the most heavily used referral center for patients with these lesions in southern Taiwan. A total of about 31,000 cases of OMF lesions from 2001-2010 was referred for histopathological examination and treated in the hospital. Therefore, despite the lack of national data of the various types of OMF lesions in Taiwan, the occurrence of such lesions among the cohort of referral patients treated in the hospital would be representative of in this geographical region.

In this follow-up study, we retrieved, from the hospital's database, the medical records of patients diagnosed with epithelial hyperplasia/hyperkeratosis, verrucous hyperplasia, oral submucous fibrosis, and lichen planus between 2001 and 2010. In addition, oral epithelial dysplasia was established based on the following histopathological findings [9]: (1) basal layer hyperplasia; (2) nuclear enlargement and hyperchromastism; (3) loss of intercellular adhesion and normal polarization; (4) abnormal mitoses above the basal cell layer; (5) individual cell keratinization within the spinous layer; (6) cellular pleomorphism; (7) drop-shaped epithelial ridges; (8) irregular stratification; and (9) an altered nuclear-cytoplasmic ratio. Epithelial dysplastic lesions were subclassified as [a] mild (dysplastic changes within the lower one-third of the oral epithelium), [b] moderate (dysplastic changes within the lower two-thirds of the oral epithelium), and [c] severe (dysplastic changes greater than two-thirds but less than the entire thickness of the oral epithelium) [10]. All the pathological diagnoses were verified and validated by two board-certified oral pathologists.

This study complied with the Helsinki Declaration with the data collected after the approval of the Institutional Review Board of Kaohsiung Medical University Hospital (KMUH-IRB-2013-0300). In order to establish which of the selected patients with potentially malignant oral epithelial lesions would actually progress to develop oral cancer, periodical follow-up assessments were arranged for all patients with a frequency based on the clinical features and the need for therapy. Those lesions without dysplastic changes would be followed-up for every 6 months while those lesions with dysplastic alterations would be followed-up for every three months. Hence, in general, patients were followed-up at least once a year and all the patients within the data sets were followed until 30 June 2010. If a clinically malignant transformation was suspected, an additional biopsy was done to confirm the diagnosis of oral cancer. The duration required for malignant transformation is defined as the time from the initial biopsy of the OPMD to the additional biopsy that confirmed the diagnosis of oral cancer. Two criteria had to be met to confirm the actual malignant transformation to oral cancer: (1) a malignant transformation lesion had to occur at the same anatomical site as the precancerous lesion, and (2) a minimum of six months was required between the initial biopsy and the additional biopsy to confirm the malignant transformation.

JMP version 9.0.1 for Windows (SAS Institute, Cary, $\mathrm{NC}$, USA) was used for all differences in the distribution of related factors in OPMDs and in the group with malignancies was estimated using a chi-square test. Time-to-event analysis involved estimating the probability that an event will occur at different points in time. The end point of follow-up in those developing cancer was the date of detection of oral malignancy, and in those lost to follow up were coded by the date of last visit, to arrive at "censored" data. Kaplan-Meier estimate was computed to estimate the probability of cancer-free survival. Cox proportional hazards model was applied to analyze the effect of single and multiple covariates in predicting cancer development. The results were considered significance when the $\mathrm{p}$-value was $<0.05$.

\section{Results}

The data sets were verified in the cancer registry database of the hospital. The cancer registry committee in the hospital will check for those cases lost to follow up. Cases, which were lost to follow up, would be checked for whether there were malignant transformations with respect to medical charts or cancer registry database in the Ministry of Health and Welfare, The Executive Yuan, Taiwan at the end of the study. Consequently, in the current study, 5071 patients were diagnosed with various 
OPMDs (4299 males and 772 females; mean age for all: 48.87 years; mean age for males: 47.70 years; mean age for females: 55.33 years; range for all: $15-96$ years; range for males: $18-96$ years; range for females: $15-95$ years). These 5071 patients with OPMDs had epithelial dysplasia with oral submucous fibrosis $(n=186,3.67 \%)$, epithelial dysplasia with epithelial hyperplasia/hyperkeratosis $(\mathrm{n}=957,18.87 \%)$; oral submucous fibrosis $(\mathrm{n}=994,19.60 \%)$, lichen planus $(\mathrm{n}=381,7.51 \%)$; verrucous hyperplasia $(\mathrm{n}=869,17.14 \%)$, and hyperkeratosis/epithelial hyperplasia $(\mathrm{n}=1684,33.21 \%)$. Additionally, a majority of these OPMD lesions were in the buccal mucosa (60.51\%), followed by the gingiva (13.65\%), and the tongue (12.46\%) (Table 1). Most of these 5071 patients presenting various OPMDs were males with the majority had the oral risk factors (alcohol drinking, betel-quid chewing, and cigarette smoking) (Table 2).

Two hundred nineteen patients (202 males, 17 females) underwent malignant transformation to oral cancers (179 OSCCs; 40 verrucous carcinomas [VCAs]). The overall transformation rate was $4.32 \%$ and the mean duration of transformation was 33.56 months (Table 3). Nine (4.84\%) of the 186 patients with epithelial dysplasia and oral submucous fibrosis in our cohort progressed to oral cancers (8 OSCCs; 1 VCA); 63 (6.58\%) of the 957 patients with epithelial dysplasia and hyperkeratosis/ epithelial hyperplasia also developed oral cancers (56 OSCCs; 7 VCAs). Moreover, a majority of these 72 patients with a malignant transformation had mild epithelial dysplasia $(n=61)$, and the remaining 11 patients had moderate $(n=6)$ or severe epithelial dysplasia $(n=5)$. Sixty-one $(6.43 \%)$ of the 949 patients with mild epithelial dysplasia, progressed to oral cancer, 6 (5.56\%) of the 108 patients with moderate epithelial dysplasia, and 5 (5.81\%) of the 86 patients with severe epithelial dysplasia progressed to oral cancer. It is worth noting that 49 (2.91\%) of 1684 patients with histologically innocent epithelial hyperplasia/hyperkeratosis underwent malignant transformation to oral cancers (37 OSCCs; 12 VCAs). In contrast, for the 59 (6.79\%) OPMDs that progressed to oral cancers in 869 patients with verrucous hyperplasia, 44 were OSCCs and 15 were VCAs. Thirty-seven $(3.72 \%)$ of the 994 patients with oral submucous fibrosis developed oral cancers (32 OSCCs; 5 VCAs). However, only $2(0.52 \%)$ of 381 patients with lichen planus developed oral cancer (2 OSCCs) (Table 3).

The most common sites for these 219 malignant transformation cases were the buccal mucosa (53.43\%), the tongue (17.81\%), and the gingiva (13.24\%). Of the 39 cases on the tongue, the predominant sites were the tongue border $(\mathrm{n}=27)$, the tongue ventrum $(\mathrm{n}=3)$, and the tongue dorsum $(n=9)$ (Table 4).

Kaplan-Meier analysis estimated the 10-year transformation rate at 0.0689 (Figure 1; Table 5). The annual malignant transformation rates are shown in Figure 2. With the exception of the lichen planus lesions, the annual rates significantly increased over time $(\mathrm{p}<0.0001)$.

Further investigation with Cox proportional hazard regression analysis was performed (Table 6). In the multiple regression models, we considered the effect of age, gender, location, lesion type and oral risk factors on malignant transformation. We found that after adjusting for other factors, lesions located on the tongue were found to have a higher malignant risk, with a hazard ratio (HRR) of 1.87 (1.29-2.67) when compared to lesions located in the buccal mucosa. The malignant transformation risk for the group with epithelial dysplasia was 1.89 times more than those without epithelial dysplasia. But the degree of epithelial dysplasia was not statistically significant with malignant transformation. Moreover, the malignant transformation rate in the current study was significantly higher ( $\mathrm{p}=0.0104$; log-rank test) (Figure 3 ) than that in our 1991-2000 study [7].

Finally, those patients older than 45 years at their first diagnosis showed significant higher malignant potential than the younger group of first diagnosis $(p=0.03)$; the male patients were significantly associated with malignant transformation when compared with female $(\mathrm{p}=0.001)$;

Table $\mathbf{1}$ Location of the $\mathbf{5 0 7 1}$ potentially malignant oral mucosal disorders in the current study

\begin{tabular}{|c|c|c|c|c|c|c|c|c|c|}
\hline Histological diagnosis & $\begin{array}{l}\text { Upper } \\
\text { lip }\end{array}$ & $\begin{array}{l}\text { Lower } \\
\text { lip }\end{array}$ & Buccal & $\begin{array}{l}\text { Mouth } \\
\text { floor }\end{array}$ & $\begin{array}{c}\text { Hard } \\
\text { palate }\end{array}$ & $\begin{array}{c}\text { Soft } \\
\text { palate }\end{array}$ & Gingiva & Tongue & Total \\
\hline $\begin{array}{l}\text { Epithelial dysplasia with oral } \\
\text { submucous fibrosis }\end{array}$ & $0(0.00)$ & $14(7.53)$ & $135(72.58)$ & $2(1.61)$ & $0(0.00)$ & $2(1.61)$ & $13(6.99)$ & $20(10.75)$ & $186(100.00)$ \\
\hline $\begin{array}{l}\text { Epithelial dysplasia with hyperkeratosis or } \\
\text { or epithelial hyperplasia }\end{array}$ & $15(1.57)$ & $64(6.69)$ & $517(54.02)$ & $24(2.51)$ & $16(1.67)$ & $32(3.34)$ & $146(15.26)$ & $143(14.94)$ & $957(100.00)$ \\
\hline Oral submucous fibrosis & $5(0.50)$ & $52(5.23)$ & $752(75.65)$ & $4(0.40)$ & $6(0.60)$ & $10(1.01)$ & $111(11.17)$ & $54(5.43)$ & $994(100.00)$ \\
\hline Lichen planus & $3(0.79)$ & $20(5.25)$ & 279 (73.22) & $1(0.26)$ & $3(0.79)$ & $0(0.00)$ & 53 (13.91) & $22(5.77)$ & $381(100.00)$ \\
\hline Verrucous hyperplasia & $15(1.72)$ & $93(10.70)$ & $401(46.14)$ & $12(1.38)$ & $20(2.30)$ & $88(10.13)$ & $119(13.69)$ & $121(13.92)$ & $869(100.00)$ \\
\hline Hyperkeratosis or epithelial hyperplasia & $12(0.71)$ & $88(5.23)$ & $966(57.36)$ & $22(1.31)$ & $25(1.48)$ & $49(2.91)$ & $250(14.85)$ & $272(16.15)$ & $1684(100.00)$ \\
\hline Total & $50(0.99)$ & $331(6.53)$ & $3050(60.15)$ & 65 (1.28) & 70 (1.38) & $181(3.57)$ & $692(13.65)$ & $632(12.46)$ & $5071(100.00)$ \\
\hline
\end{tabular}

Data are $\mathrm{N}(\%)$. 
Table 2 Age, gender and oral risk factors of the $\mathbf{5 0 7 1}$ potentially malignant oral mucosal disorders in the current study

\begin{tabular}{|c|c|c|c|c|c|c|c|c|c|c|}
\hline & \multirow[b]{2}{*}{$\mathbf{N}$} & \multirow{2}{*}{$\begin{array}{c}\text { Age } \\
\text { Mean } \pm \text { Standard deviation }\end{array}$} & \multicolumn{2}{|c|}{ Gender } & \multicolumn{2}{|c|}{ Alcohol drinking } & \multicolumn{2}{|c|}{ Betel-quid chewing } & \multicolumn{2}{|c|}{ Cigarette smoking } \\
\hline & & & $\begin{array}{l}\text { Male } \\
\text { N (\%) }\end{array}$ & $\begin{array}{l}\text { Female } \\
\mathrm{N}(\%)\end{array}$ & $\begin{array}{l}\text { Yes } \\
\mathrm{N}(\%)\end{array}$ & $\begin{array}{l}\text { No } \\
\text { N (\%) }\end{array}$ & $\begin{array}{l}\text { Yes } \\
\mathrm{N}(\%)\end{array}$ & $\begin{array}{l}\text { No } \\
\text { N (\%) }\end{array}$ & $\begin{array}{l}\text { Yes } \\
\mathrm{N}(\%)\end{array}$ & $\begin{array}{l}\text { No } \\
\text { N (\%) }\end{array}$ \\
\hline Epithelial dysplasia with oral submucous fibrosis & 186 & $47.74 \pm 11.84$ & $177(95.16)$ & $9(4.84)$ & $141(75.81)$ & $45(24.19)$ & $166(89.25)$ & $20(10.75)$ & $164(88.17)$ & $22(11.83)$ \\
\hline $\begin{array}{l}\text { Epithelial dysplasia with hyperkeratosis or epithelial } \\
\text { hyperplasia }\end{array}$ & 957 & $51.65 \pm 12.69$ & $828(86.52)$ & $129(13.48)$ & $702(73.35)$ & $255(26.65)$ & 852 (89.03) & $105(10.97)$ & $824(86.10)$ & $133(13.90)$ \\
\hline Hyperkeratosis or epithelial hyperplasia & 1684 & $48.70 \pm 13.64$ & $1422(84.44)$ & $262(15.56)$ & $1226(72.80)$ & $458(27.20)$ & $1489(88.42)$ & $195(11.58)$ & $1457(86.52)$ & $227(13.48)$ \\
\hline Oral submucous fibrosis & 994 & $44.69 \pm 12.43$ & $914(91.95)$ & $80(8.05)$ & $728(73.24)$ & $266(26.76)$ & $879(88.43)$ & $115(11.57)$ & $857(86.2)$ & $137(13.8)$ \\
\hline Lichen planus & 381 & $51.08 \pm 13.22$ & 149 (39.11) & $232(60.89)$ & $272(71.65)$ & $108(28.35)$ & 345 (90.55) & $36(9.45)$ & $334(87.66)$ & $47(12.34)$ \\
\hline Verrucous hyperplasia & 869 & $50.16 \pm 12.09$ & $809(93.10)$ & $60(6.90)$ & 645 (74.22) & $224(25.78)$ & 747 (85.96) & $122(14.04)$ & 735 (84.58) & $134(15.42)$ \\
\hline
\end{tabular}


Table 3 Number, percentage and mean duration of the malignant transformation for the $\mathbf{2 1 9}$ potentially malignant oral epithelial lesions with different histological diagnoses

\begin{tabular}{lcc}
\hline Histological diagnosis & $\begin{array}{c}\text { Malignant } \\
\text { transformation }\end{array}$ & $\begin{array}{c}\text { Mean duration } \\
\text { of malignant } \\
\text { transformation } \\
\text { (months) }\end{array}$ \\
\hline $\begin{array}{l}\text { Epithelial dysplasia with oral } \\
\text { submucous fibrosis }\end{array}$ & $9 / 186(4.84)$ & 42.47 \\
$\begin{array}{l}\text { Epithelial dysplasia with } \\
\text { hyperkeratosis or epithelial }\end{array}$ & $63 / 957(6.58)$ & 27.86 \\
hyperplasia & & \\
$\begin{array}{l}\text { Oral submucous fibrosis } \\
\text { Lichen planus }\end{array}$ & $37 / 994(3.72)$ & 37.42 \\
Verrucous hyperplasia & $2 / 381(0.52)$ & 8.07 \\
$\begin{array}{l}\text { Hyperkeratosis or epithelial } \\
\text { hyperplasia }\end{array}$ & $59 / 869(6.79)$ & 33.49 \\
Overall & $49 / 1684(2.91)$ & 36.55 \\
\hline
\end{tabular}

the oral risk factors were not associated with malignant transformation (Table 7).

\section{Discussion}

Two important parameters should be considered when evaluating the potential for malignant transformation of OPMDs. First, the initial OPMD lesions should be confirmed using histopathological diagnoses; second, the amount of time it takes for the lesion to be transformed into a malignancy at the same location as the original OPMD lesion. In the present study, we included a wide spectrum of histopathologically diagnosed OPMDs and specified that the time from the initial presentation of the precancerous lesion to the malignant transformation must be at least six months and that the transformation must occur at the same site as the initial biopsy. We found that the overall malignant transformation rate of the OPMDs in our cohort was approximately $4 \%$, which was lower than that of other studies [11-14] on the malignant transformation of precancerous lesions of leukoplakia. The reason for this difference may be that our study was based on the histopathological diagnoses of different kinds of precancerous oral lesions.

Epithelial dysplasia is a critical factor in determining malignant potential. In this study, $6.30 \%$ cases of epithelial dysplasia (72/1143: 83.03\% (60) mild; $16.97 \%$ (12) moderate and severe) transformed into oral cancers, fewer than in another study [15] based on a relatively small Chinese sample in which the rate of malignant transformation was 26.8\% (37/138: 28.6 (10/35) cases of moderate-to-severe epithelial dysplasia. One explanation for this difference might be that the majority of our cohort had mild epithelial dysplastic lesions, which usually have a lower risk of malignant transformation potential [15-17], and another might be that our sample of epithelial dysplastic lesions was 8.28 times larger (1143 vs. 138).

Using Cox proportional hazards regression analysis, we showed the potential effect of the degree of epithelial dysplasia on the malignant transformation rate and found that the risk of malignant transformation was 1.89 times higher for patients with dysplastic changes of precancerous lesions than for those without dysplastic changes. This is consistent with Amagasa et al. [12], who found that the rate of malignant transformation in patients with leukoplakia and epithelial dysplasia was much higher than that of patients without epithelial dysplasia (13.3\% vs. $3.0 \%)$. Our finding was also compatible with a report from Northern Ireland [18], which indicated that $15 \%$ of their sample with epithelial dysplasia $(25 / 167)$ had a malignant transformation, while only $1 \%$ without dysplastic changes $(12 / 118)$ did, and that the risk of a malignant transformation for patients with severe epithelial dysplasia was significantly higher than for patients with mild epithelial dysplasia. Cowan et al. [18] found no significant difference in the risk between patients with moderate and mild epithelial dysplasia. These findings contrast with a report [15] on a Chinese population in which the malignant transformation risk

Table 4 Locations of the $\mathbf{2 1 9}$ potentially malignant oral epithelial lesions with malignant transformation

\begin{tabular}{|c|c|c|c|c|c|c|c|c|c|}
\hline Histological diagnosis & $\begin{array}{l}\text { Upper } \\
\text { lip }\end{array}$ & $\begin{array}{l}\text { Lower } \\
\text { lip }\end{array}$ & Buccal & $\begin{array}{l}\text { Mouth } \\
\text { floor }\end{array}$ & $\begin{array}{c}\text { Hard } \\
\text { palate }\end{array}$ & $\begin{array}{c}\text { Soft } \\
\text { palate }\end{array}$ & Gingiva & Tongue $^{a}$ & Total \\
\hline Epithelial dysplasia with oral submucous fibrosis & $0(0.00)$ & $0(0.00)$ & $6(66.67)$ & $0(0.00)$ & $0(0.00)$ & $0(0.00)$ & $0(0.00)$ & $3(0.33)$ & $9(100.00)$ \\
\hline $\begin{array}{l}\text { Epithelial dysplasia with hyperkeratosis or } \\
\text { epithelial hyperplasia }\end{array}$ & $2(3.17)$ & $8(12.70)$ & $27(42.86)$ & $4(6.35)$ & $1(1.59)$ & $4(6.34)$ & $5(7.94)$ & $12(19.05)$ & $63(100.00)$ \\
\hline Oral submucous fibrosis & $0(0.00)$ & $0(0.00)$ & $25(167.57)$ & $0(0.00)$ & $0(0.00)$ & $2(5.41)$ & $5(13.51)$ & $5(13.51)$ & $37(100.00)$ \\
\hline Lichen planus & $0(0.00)$ & $0(0.00)$ & $0(0.00)$ & $0(0.00)$ & $0(0.00)$ & $0(0.00)$ & $0(0.00)$ & $2(100.00)$ & $2(100.00)$ \\
\hline Verrucous hyperplasia & $0(0.00)$ & $5(8.47)$ & $32(54.24)$ & $0(0.00)$ & $1(1.69)$ & $4(6.78)$ & $9(15.25)$ & $8(13.56)$ & $59(100.00)$ \\
\hline Hyperkeratosis or epithelial hyperplasia & $0(0.00)$ & $2(4.08)$ & $27(55.10)$ & $0(0.00)$ & $0(0.00)$ & $1(2.04)$ & $10(20.41)$ & $9(18.37)$ & $49(100.00)$ \\
\hline Total & $2(0.91)$ & $15(6.85)$ & $117(53.42)$ & $4(1.83)$ & $2(0.91)$ & $11(5.02)$ & $29(13.24)$ & $39(17.81)$ & $219(100.00)$ \\
\hline
\end{tabular}

Data are $\mathrm{N}(\%) ;{ }^{a}$ Tongue border: 27 ; tongue ventrum: 3; tongue dorsum: 9. 


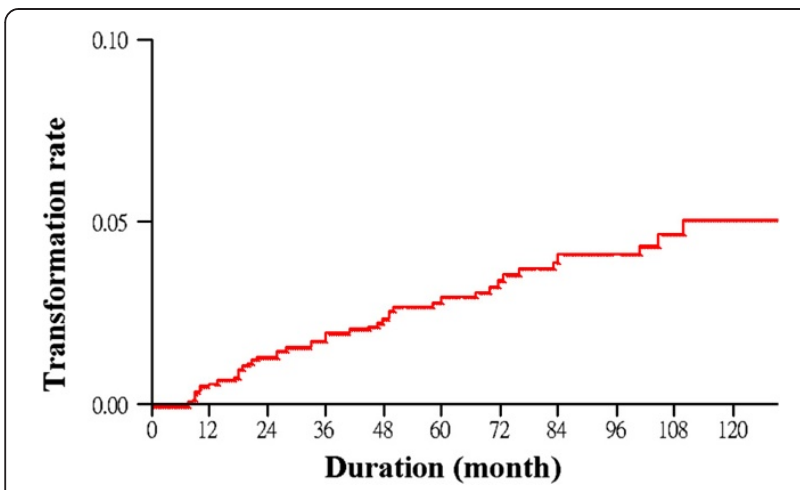

Figure 1 The annual malignant transformation rate of the current study.

for cases of moderate and severe epithelial dysplasia was 2.78 times higher than for cases of mild epithelial dysplasia $(p=0.002)$. This disparity might be due to the relatively low number of cases of moderate and severe epithelial dysplasia in our cohort because of the usual early local excision for the diagnosed cases of moderate and severe epithelial dysplasia in the hospital.

In the current study, 49 (2.91\%) cases of histologically innocent hyperkeratosis/epithelial hyperplasia, with an average duration of 36.55 months, transformed into oral cancer. These data were compatible with two studies $[7,8]$ on hyperkeratosis/epithelial hyperplasia cases with malignant transformation rates of $3.55 \%$ and $8.57 \%$ (mean duration: 41.30 months and 32.94 months), respectively.

Oral submucous fibrosis is a chronic condition of the oral mucosa in Asians, especially Indians $[19,20]$. In our cohort, 37 (3.72\%) of 994 cases of oral submucous fibrosis transformed into malignancies with an average duration of 37.42 months, which was a higher

Table 5 Annual malignant transformation rate (Kaplan-Meier estimates) of the current study

\begin{tabular}{cccc}
\hline $\begin{array}{c}\text { Time } \\
\text { (years) }\end{array}$ & $\begin{array}{c}\text { Transformation } \\
\text { rate }\end{array}$ & $\begin{array}{c}\text { Standard } \\
\text { error }\end{array}$ & $\begin{array}{c}\text { 95\% confidence } \\
\text { interval }\end{array}$ \\
\hline 1 & 0.0119 & 0.0015 & $0.0093-0.0154$ \\
2 & 0.0232 & 0.0022 & $0.0192-0.0279$ \\
3 & 0.0290 & 0.0025 & $0.0244-0.0343$ \\
4 & 0.0385 & 0.0030 & $0.0329-0.0449$ \\
5 & 0.0461 & 0.0034 & $0.0398-0.0534$ \\
6 & 0.0543 & 0.0039 & $0.0471-0.0624$ \\
7 & 0.0594 & 0.0042 & $0.0517-0.0681$ \\
8 & 0.0615 & 0.0044 & $0.0535-0.0706$ \\
9 & 0.0669 & 0.0050 & $0.0578-0.0773$ \\
10 & 0.0689 & 0.0053 & $0.0592-0.0802$ \\
\hline
\end{tabular}

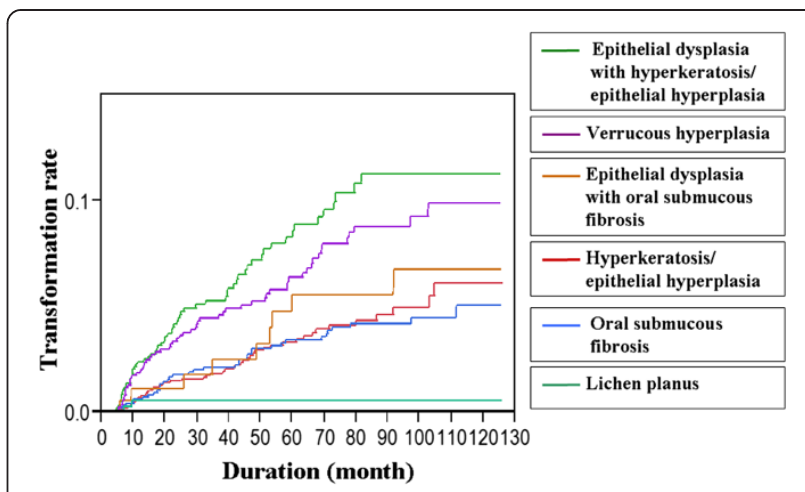

Figure $\mathbf{2}$ The annual malignant transformation rate of oral potentially malignant disorders ( $<0.0001$; log-rank test).

transformation rate $(1.9 \%)$ and a shorter mean duration for transformation (52.3 months) than in our 1991-2001 study [7]. This reflects not only the higher incidence rate of oral cancer within recent years, but also that the general public is more aware of Taiwan's oral cancer pre-screening health promotion program and periodic clinical follow-up: For those persons ( $\geq 30$ years old) who are the current/ex alcohol drinkers/betel-quid chewers/cigarette smokers are encouraged to receive oral examination for the possible presentation of OPMDs by the medical doctors (chiefly, Family Medicine, and Ear Nose and Throat specialties) as well as the dentists who have been trained for oral screening of the OPMDs from the local clinics or hospitals. The patients with suspected lesions of OPMDs will then be referred to the hospitals having oral biopsy service for histological confirmation. Furthermore, two months later, the government will check whether the referral patients have actually received oral biopsy procedures. Cases of malignant transformation also increased and the mean transformation time decreased. In contrast, of 66 patients followed-up for 17 years, 5 (7.6\%) patients had OPMDs transform into OSCC in an Indian study [19], which was higher than in our study; this variation may reflect a larger sample size along with more stringent inclusion criteria in our study.

Oral lichen planus is an inflammatory mucocutaneous condition; its etiological factors are not yet completely certain [21]. It tends to occur in the buccal mucosa of 40-50-year-old women (female:male ratio $=2: 1$ ), [22]. In our study, women (average age at onset: 51.08 years) accounted for $60.89 \%$ of the cases of oral lichen planus, and $73.22 \%$ were in the buccal mucosa. The World Health Organization (WHO) recognizes oral lichen planus as an OPMD [6]. The transformation rate of oral lichen planus in the current study was $0.52 \%$, which was lower than the $2.10 \%$ rate in our 1991-2001 study [7] but compatible with two other studies $(0.4 \%, 0.5 \%$, respectively) $[23,24]$. In the present study, the mean time 
Table 6 Proportional hazards model of malignant transformation for related factors of the current study

\begin{tabular}{|c|c|c|c|c|c|}
\hline Factor & $\mathrm{N}(\%)$ & Crude RR $(95 \% \mathrm{Cl})$ & p-value & ARR $(95 \% \mathrm{CI})$ & $\mathrm{p}$-value \\
\hline \multicolumn{6}{|l|}{ Location } \\
\hline Buccal & $3050(60.15)$ & 1 & & 1 & \\
\hline Tongue & $632(12.46)$ & $1.83(1.26-2.60)$ & 0.002 & $1.87(1.29-2.67)$ & 0.0014 \\
\hline Others & $1389(27.39)$ & $1.30(0.95-1.76)$ & 0.09 & $1.33(0.98-1.81)$ & 0.07 \\
\hline \multicolumn{6}{|l|}{ Gender } \\
\hline Female & $772(15.22)$ & 1 & & 1 & \\
\hline Male & $4299(84.78)$ & $2.16(1.36-3.68)$ & 0.0007 & $2.15(1.35-3.67)$ & 0.0008 \\
\hline \multicolumn{6}{|c|}{ Epithelial dysplasia (ED) } \\
\hline No & $3928(77.46)$ & 1 & & 1 & \\
\hline Yes & $1143(22.54)$ & $1.98(1.48-2.61)$ & $<0.0001$ & $1.89(1.39-2.54)$ & $<.0001$ \\
\hline \multicolumn{6}{|l|}{ Degree of ED } \\
\hline Mild & 949 (83.03) & 1 & & 1 & \\
\hline Moderate & $108(9.45)$ & $1.96(0.77-4.05)$ & 0.14 & $1.18(0.46-2.52)$ & 0.70 \\
\hline Severe & $86(7.52)$ & $2.03(0.72-4.41)$ & 0.16 & $1.08(0.38-2.43)$ & 0.88 \\
\hline \multicolumn{6}{|l|}{ Alcohol drinking } \\
\hline No & $1356(26.74)$ & 1 & & 1 & \\
\hline Yes & $3715(73.26)$ & $0.77(0.58-1.02)$ & 0.07 & $0.71(0.53-0.96)$ & 0.02 \\
\hline \multicolumn{6}{|c|}{ Betel-quid chewing } \\
\hline No & $593(11.69)$ & 1 & & 1 & \\
\hline Yes & $4478(88.31)$ & $0.83(0.38-1.25)$ & 0.38 & $1.71(0.79-3.37)$ & 0.16 \\
\hline \multicolumn{6}{|c|}{ Cigarette smoking } \\
\hline No & $700(13.80)$ & 1 & & 1 & \\
\hline Yes & $4371(86.20)$ & $0.73(0.52-1.04)$ & 0.08 & $0.42(0.23-0.85)$ & 0.02 \\
\hline
\end{tabular}

needed for oral lichen planus to malignantly transform was 8.07 months, much shorter than for the other five types of OPMDs. This might be attributable to the small sample size $(n=2)$; in addition, one of these patients also had epithelial dysplasia.

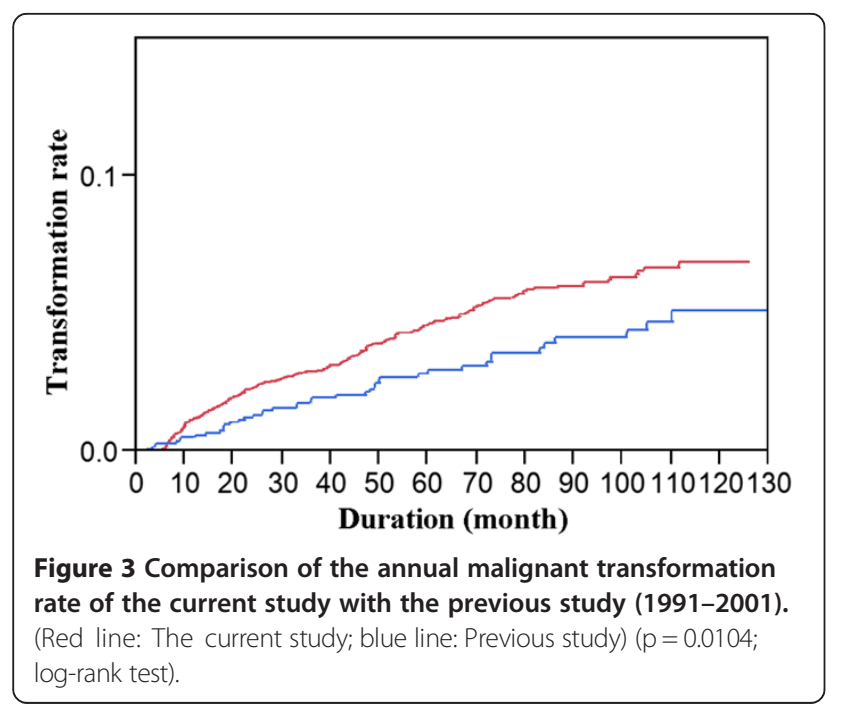

Verrucous hyperplasia in the oral cavity has also been regarded as an OPMD and can develop into an OSCC or a VCA [25]. In the current study, 59 (6.79\%) of 869 patients with verrucous hyperplasia developed oral cancer. The mean duration of 33.49 months was shorter than the 54.6 months in our 1991-2001 study [7], but the rate of malignant transformation was higher $(10 / 324,3.09 \%)$. In contrast, the rate of malignant transformation of our cohort was lower and the mean duration of transformation was shorter than in two other studies with relatively small sample sizes: Wang et al. [26] (10/60, 3.09\%; 22.0 months) and Ho et al. [8] (9/44, 20.00\%; 41.87 months).

We found that the average duration of malignant transformation was 33.6 months, shorter than in other studies $[7,8]$. Most of the OPMDs in our cohort were in the buccal mucosa (60.15\%), the gingiva (13.65\%), and the tongue (12.46\%). Most of the 219 OPMDs with a malignant transformation in our cohort were in the buccal mucosa (53.43\%), the tongue (17.81\%), and gingiva (13.24\%). However, we found that OPMDs in the tongue had a higher malignant transformation potential than those in the buccal mucosa $(\mathrm{HRR}=1.83)$, which 
Table 7 The analyses of age, sex and oral risk factors with malignant transformation in patients with OPMDs of the current study

\begin{tabular}{|c|c|c|c|}
\hline & & ant transform & \\
\hline & $\begin{array}{c}\text { Yes } \\
\text { N (\%) }\end{array}$ & $\begin{array}{c}\text { No } \\
\text { N (\%) }\end{array}$ & $p$-value \\
\hline Age (years) & & & \\
\hline$\leq 45$ & 71 (32.42) & $1953(40.25)$ & 0.03 \\
\hline$>45$ & 148 (67.58) & 2899 (59.75) & \\
\hline Sex & & & \\
\hline Male & $202(92.23)$ & 4097 (84.44) & 0.001 \\
\hline Female & $17(7.77)$ & 755 (15.56) & \\
\hline Alcohol drink & & & \\
\hline No & 70 (31.96) & $1286(26.50)$ & 0.09 \\
\hline Yes & 149 (68.04) & $3566(73.50)$ & \\
\hline Betel-quid ch & & & \\
\hline No & $30(13.70)$ & $563(11.60)$ & 0.33 \\
\hline Yes & 189 (86.30) & $4289(88.40)$ & \\
\hline Cigarette sme & & & \\
\hline No & 40 (18.26) & $660(13.60)$ & 0.057 \\
\hline Yes & 179 (81.74) & $4192(86.40)$ & \\
\hline
\end{tabular}

agreed with Amagasa et al. [12] and two studies from India $[27,28]$.

We also found that the risk of malignant transformation was significantly higher for males than for females (HRR $=2.16$ ). With the exception of two patients with lichen planus (one male, one female), all other types of malignant transformation showed that the male patients had a higher risk than did the female patients, which was consistent with the previous studies in India $[27,28]$. This might be because more males than females in Taiwan chew betelquid, and more males habitually chew tobacco and smoke in India.

The three highest annual malignant transformation rates in the current study, in descending order, were epithelial dysplasia with hyperkeratosis/epithelial hyperplasia, verrucous hyperplasia, and epithelial dysplasia with oral submucous fibrosis. This indicates the significance of the malignant transformation of these three OPMDs and the potential impact of dysplastic changes on transformation. The annual malignant transformation rates of hyperkeratosis/ epithelial hyperplasia and oral submucous fibrosis lesions were similar for the first 7 years. However, the transformation rate of hyperkeratosis/oral submucous fibrosis was significantly higher than that of oral submucous fibrosis after the 7th year, which indicated that despite the histological innocence of the hyperkeratosis/ epithelial hyperplasia lesions, a long-term follow-up should be implemented.
Finally, the overall transformation rate of the current study (2001-2010) was compatible with that of our 1991-2001 study [7] (4.32\% vs. 3.02\%); however, a log-rank test showed that the annual transformation rate was significantly higher in the first 10 years in the current study than in our previous study.

\section{Conclusion}

In the current study, we analyzed and updated the data of malignant transformation of various OPMDs in a cohort of patients from southern Taiwan. Moreover, our data indicated that patients with OPMDs need a long-term clinical follow-up and histopathological examination is an important predictor of cancer development to monitor the possibility of malignant transformation. Nevertheless, it should be cautioned that the current research was a follow-up study based in a Taiwanese hospital; a national based research is encouraged.

\section{Abbreviations}

OPMD: Oral potentially malignant disorders; OMF: Oral and Maxillofacial; HRR: Hazard rate ratio; VCA: Verrucous carcinoma; OSCC: Oral squamous cell carcinoma; WHO: World Health Organization.

\section{Competing interests}

The authors declare that they have no competing interests.

\section{Authors' contributions}

YHT, YYW, and YKC are the primary writers of the manuscript and participated in the study implementing. YKC conceived of the study, and had made substantial contributions to conception and design, and revised the manuscript critically for important intellectual content. YHT, YYW, and YKC assisted in statistical analysis, interpretation of data and draft the statistical analysis of manuscript. CHC, YKC, WCW, CYC, and YKC are the principal investigators of clinical studies in this project. All authors read and approved the final manuscript.

\section{Acknowledgements}

The authors are grateful to health and welfare surcharge of tobacco products, the Ministry of Health and Welfare, Taiwan, Republic of China (grant \# MOHW103-TD-B-111-05) and to the Taiwan National Science Council (grant \# NSC 102-3114-Y-492-076-023) for financial support.

\section{Author details}

${ }^{1}$ Department of Clinical Research, Kaohsiung Medical University Hospital, Kaohsiung, Taiwan. ${ }^{2}$ Instrument Technology Research Center, National Applied Research Laboratories, Hsinchu City 300, Taiwan. ${ }^{3}$ Division of Oral and Maxillofacial Surgery, Department of Dentistry, Kaohsiung Medical University Hospital, Kaohsiung, Taiwan. ${ }^{4}$ Division of Oral Pathology and Maxillofacial Radiology, Kaohsiung Medical University Hospital, Kaohsiung, Taiwan. ${ }^{5}$ School of Dentistry, College of Dental Medicine, Kaohsiung Medical University, Kaohsiung, Taiwan. ${ }^{6}$ Oral \& Maxillofacial Imaging Center, Kaohsiung Medical University, Kaohsiung, Taiwan.

Received: 8 April 2014 Accepted: 23 July 2014

Published: 5 August 2014

\section{References}

1. Tang H, Wu Z, Zhang J, Su B: Salivary IncRNA as a potential marker for oral squamous cell carcinoma diagnosis. Mol Med Rep 2013, 7(3):761-766.

2. Cheng YS, Rees T, Wright J: A review of research on salivary biomarkers for oral cancer detection. Clin Transl Med 2014, 3(1):3.

3. Tovosia S1, Chen PH, Ko AM, Tu HP, Tsai PC, Ko YC: Prevalence and associated factors of betel quid use in the Solomon Islands: a hyperendemic area for oral and pharyngeal cancer. Am J Trop Med Hyg 2007, 77(3):586-590. 
4. Health Promotion Administration, Ministry of Health and Welfare: Cancer Registry Annual Report 2011 Taiwan. 2014, 3-17.

5. Scott SE, Grunfeld EA, McGurk M: The idiosyncratic relationship between diagnostic delay and stage of oral squamous cell carcinoma. Oral Oncol 2005, 41(4):396-403.

6. van der Waal I: Potentially malignant disorders of the oral and oropharyngeal mucosa; terminology, classification and present concepts of management. Oral Oncol 2009, 45(4-5):317-323.

7. Hsue SS, Wang WC, Chen CH, Lin CC, Chen YK, Lin LM: Malignant transformation in 1458 patients with potentially malignant oral mucosal disorders: a follow-up study based in a Taiwanese hospital. J Oral Pathol Med 2007, 36(1):25-29.

8. Ho PS, Chen PL, Warnakulasuriya S, Shieh TY, Chen YK, Huang IY: Malignant transformation of oral potentially malignant disorders in males: a retrospective cohort study. BMC Cancer 2009, 9:260.

9. Pindborg JJ, Daftary DK, Mehta FS: A follow-up study of sixty-one oral dysplastic precancerous lesions in Indian villagers. Oral Surg Oral Med Oral Pathol 1977, 43(3):383-390.

10. Wright A, Shear M: Epithelial dysplasia immediately adjacent to oral squamous cell carcinomas. J Oral Pathol 1985, 14(7):559-564.

11. Schepman KP, van der Meij EH, Smeele LE, van der Waal I: Malignant transformation of oral leukoplakia: a follow-up study of a hospital-based population of 166 patients with oral leukoplakia from The Netherlands. Oral Oncol 1998, 34(4):270-275.

12. Amagasa $\mathrm{T}$, Yamashiro $\mathrm{M}$, Ishikawa $\mathrm{H}$ : Oral leukoplakia related to malignant transformation. Oral Science International 2006, 3(2):45-55.

13. Gangadharan P, Paymaster JC: Leukoplakia-an epidemiologic study of 1504 cases observed at the Tata Memorial Hospital, Bombay India. $\mathrm{Br} J$ Cancer 1971, 25(4):657-668.

14. Silverman S Jr, Gorsky M, Lozada F: Oral leukoplakia and malignant transformation. A follow-up study of 257 patients. Cancer 1984, 53(3):563-568.

15. Liu W, Bao ZX, Shi LJ, Tang GY, Zhou ZT: Malignant transformation of oral epithelial dysplasia: clinicopathological risk factors and outcome analysis in a retrospective cohort of 138 cases. Histopathology 2011, 59(4):733-740.

16. Kumar A, Cascarini L, McCaul JA, Kerawala CJ, Coombes D, Godden D, Brennan PA: How should we manage oral leukoplakia? Br J Oral Maxillofac Surg 2013, 51(5):377-383.

17. Ho MW, Field EA, Field JK, Risk JM, Rajlawat BP, Rogers SN, Steele JC, Triantafyllou A, Woolgar JA, Lowe D, Shaw RJ: Outcomes of oral squamous cell carcinoma arising from oral epithelial dysplasia: rationale for monitoring premalignant oral lesions in a multidisciplinary clinic. Br J Oral Maxillofac Surg 2013, 51(7):594-599.

18. Cowan CG, Gregg TA, Napier SS, McKenna SM, Kee F: Potentially malignant oral lesions in northern Ireland: a 20-year population-based perspective of malignant transformation. Oral Dis 2001, 7(1):18-24.

19. Pindborg JJ, Sirsat SM: Oral submucous fibrosis. Oral Surg Oral Med Oral Pathol 1966, 22(6):764-779.

20. Canniff JP, Harvey W, Harris M: Oral submucous fibrosis: its pathogenesis and management. Br Dent J 1986, 160(12):429-434.

21. Farhi D, Dupin N: Pathophysiology, etiologic factors, and clinical management of oral lichen planus, part l: facts and controversies. Clin Dermatol 2010, 28(1):100-108.

22. Shen ZY, Liu W, Zhu LK, Feng JQ, Tang GY, Zhou ZT: A retrospective clinicopathological study on oral lichen planus and malignant transformation: analysis of 518 cases. Med Oral Patol Oral Cir Bucal 2012, 17(6):e943-e947.

23. Sigurgeirsson B, Lindelof B: Lichen planus and malignancy. An epidemiologic study of 2071 patients and a review of the literature. Arch Dermatol 1991, 127(11):1684-1688.

24. Rodstrom PO, Jontell M, Mattsson U, Holmberg E: Cancer and oral lichen planus in a Swedish population. Oral Oncol 2004, 40(2):131-138.

25. Hazarey VK1, Ganvir SM, Bodhade AS: Verrucous hyperplasia: a clinico-pathological study. J Oral Maxillofac Pathol 2011, 15(2):187-191.

26. Wang YP, Chen HM, Kuo RC, Yu CH, Sun A, Liu BY, Kuo YS, Chiang CP: Oral verrucous hyperplasia: histologic classification, prognosis, and clinical implications. J Oral Pathol Med 2009, 38(8):651-656.

27. Silverman S, Bhargava K, Smith LW, Malaowalla AM: Malignant transformation and natural history of oral leukoplakia in 57,518 industrial workers of Gujarat India. Cancer 1976, 38(4):1790-1795.
28. Gupta PC, Mehta FS, Daftary DK, Pindborg JJ, Bhonsle RB, Jalnawalla PN, Sinor PN, Pitkar VK, Murti PR, Irani RR, Shah HT, Kadam PM, lyer KS, lyer HM, Hegde AK, Chandrashekar GK, Shiroff BC, Sahiar BE, Mehta MN: Incidence rates of oral cancer and natural history of oral precancerous lesions in a 10-year follow-up study of Indian villagers. Community Dent Oral Epidemiol 1980, 8(6):283-333.

doi:10.1186/1472-6831-14-99

Cite this article as: Wang et al:: Malignant transformation in 5071 southern Taiwanese patients with potentially malignant oral mucosal disorders. BMC Oral Health 2014 14:99.

\section{Submit your next manuscript to BioMed Central and take full advantage of:}

- Convenient online submission

- Thorough peer review

- No space constraints or color figure charges

- Immediate publication on acceptance

- Inclusion in PubMed, CAS, Scopus and Google Scholar

- Research which is freely available for redistribution 